\title{
Hamartomatous Polyp of Minor Salivary Gland Arising in the Tongue: A Report of the First Case
}

\author{
Yosep Chong1, Young Hak Park2 ${ }^{\text {, Tae-Jung Kim1, Chang Suk Kang1* }}$ \\ ${ }^{1}$ Department of Hospital Pathology, Yeouido St. Mary's Hospital, The Catholic University of Korea College of \\ Medicine, Seoul, South Korea \\ ${ }^{2}$ Department of Otolaryngology-Head and Neck Surgery, Yeouido St. Mary's Hospital, The Catholic University of \\ Korea College of Medicine, Seoul, South Korea \\ Email: ${ }^{\text {cskang@catholic.ac.kr }}$
}

Received 15 April 2014; revised 15 May 2014; accepted 5 June 2014

Copyright @ 2014 by authors and Scientific Research Publishing Inc.

This work is licensed under the Creative Commons Attribution International License (CC BY).

http://creativecommons.org/licenses/by/4.0/

(c) (i) Open Access

\begin{abstract}
Benign tumorous condition can be encountered at very unusual location in oral cavity and pharyngeal region, which leads diagnostic difficulty. Here we describe a very unusual presentation of polypoid hamartoma on the root of the tongue. A 59-year-old woman presented with a polypoid tumor mass on the dorsal root of the tongue. Microscopically, it was hamartoma showing normal salivary glands of mucinous and serous types, lymphoid hyperplasia, and skeletal muscle bundles. Major differential diagnoses include accessory tongue, adenomatoid hyperplasia, and idiopathic hyperplasia of sublingual glands. To our knowledge, this is the first report of hamartoma arising in the root of the tongue presenting as polypoid mass. Correct diagnosis based on pathologic examination is essential for proper treatment.
\end{abstract}

\section{Keywords}

Hamartoma, Minor Salivary Gland, Tongue Neoplasm, Polyps

\section{Introduction}

Various soft-tissue lesions of the oral cavity that present as tumors are commonly observed in daily practice. Such benign lesions include irritation fibroma, peripheral ossifying fibroma, pyogenic granuloma, peripheral giant-cell granuloma, salivary gland choristoma, granular cell tumor, verruciform xanthoma, hairy polyp, and

${ }^{*}$ Corresponding author.

How to cite this paper: Chong, Y., Park, Y.H., Kim, T.-J. and Kang, C.S. (2014) Hamartomatous Polyp of Minor Salivary Gland Arising in the Tongue: A Report of the First Case. Open Journal of Pathology, 4, 83-85. 
mesenchymal tumors such as leiomyoma, rhabdomyoma, schwannoma, neurofibroma, traumatic neuroma, lipoma, hemangioma, and solitary fibrous tumor [1] [2]. In addition, adenomatoid hyperplasia of minor salivary glands, idiopathic hyperplasia of sublingual glands, and various types of malignant lymphoma can also be presented as polypoid tumor-like lesions [3]-[5].

Recently, we experienced a very unusual hamartomatous lesion of the minor salivary gland presenting as a pedunculated polyp on the base of the tongue in a 59-year-old woman. To the best of our knowledge, such a case has not previously been reported. Here, we present the case with a brief review of the current literature.

\section{Case Presentation}

A 59-year-old woman presented with a polypoid mass on the dorsal root of the tongue. She did not complain of pain or tenderness but had a little difficulty swallowing. She had no history of local trauma in the oral cavity such as dental extraction surgery.

On laryngoscopic examination, the mass was a $1.5 \times 1.2$-cm pedunculated polypoid mass with normal-appearing mucosa arising in the base of the tongue (Figure 1). The tumor was attached to the base of the tongue by a stalk and generally looked benign. The relationship of the tumor and the tongue is illustrated in Figure 1(B). The mass was removed under local anesthesia.

On microscopic examination, it consisted of a lobulated mass of normal salivary glands of mucinous and serous types with loose connective tissue and normal overlying mucosa. Multifocal areas of submucosal soft tissue showed lymphoid hyperplasia that could be considered part of the lingual tonsils. The inner region of the tumor showed skeletal muscle bundles (H\&E stain) (Figure 2).

Magnetic resonance imaging performed after surgical removal revealed no suspicious local invasion or remnant tumor in the resected area.

\section{Conclusions}

The major differential diagnosis of this case was accessory tongue, adenomatoid hyperplasia of minor salivary glands, and tumorous presentation of idiopathic hyperplasia of sublingual glands. Tongue anomalies such as accessory tongue can be ruled out by the fact that the tumor had not been present since birth [6]. Although our case also had a muscular component in the core of the lesion, it was mainly composed of normal lobulated salivary glands. Adenomatoid hyperplasia of minor salivary glands could also be considered in this case. However, the salivary glands in adenomatoid hyperplasia are more hyperplastic and composed of only mucinous glands [1]. Furthermore, the muscular component in this case cannot be explained by adenomatoid hyperplasia. Idiopathic hyperplasia of sublingual glands can also present as a tumorous lesion; however, it presents as a sessile lesion in the retromolar area and is usually associated with an edentulous condition [3]-[5].

\section{Summary}

Because of the anatomical complexity of head and neck region, benign conditions mimicking tumor can be easily
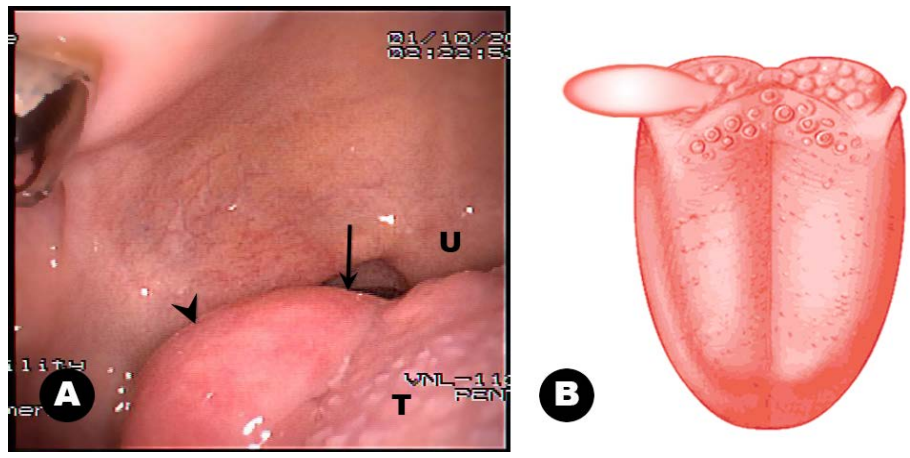

Figure 1. Laryngoscopic finding and graphic illustration. (A) An ovoid polypoid mass is noted on the right dorsal surface of the tongue base (arrowhead). The stalk of the mass is indicated by an arrow. Note the circumvallate papillae on the tongue base (U; uvula, T; tongue). (B) Illustration of the polypoid mass showing its relationship to the tongue. 


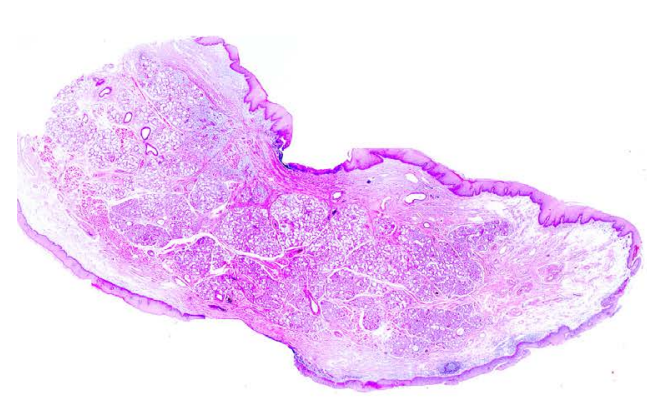

(A)
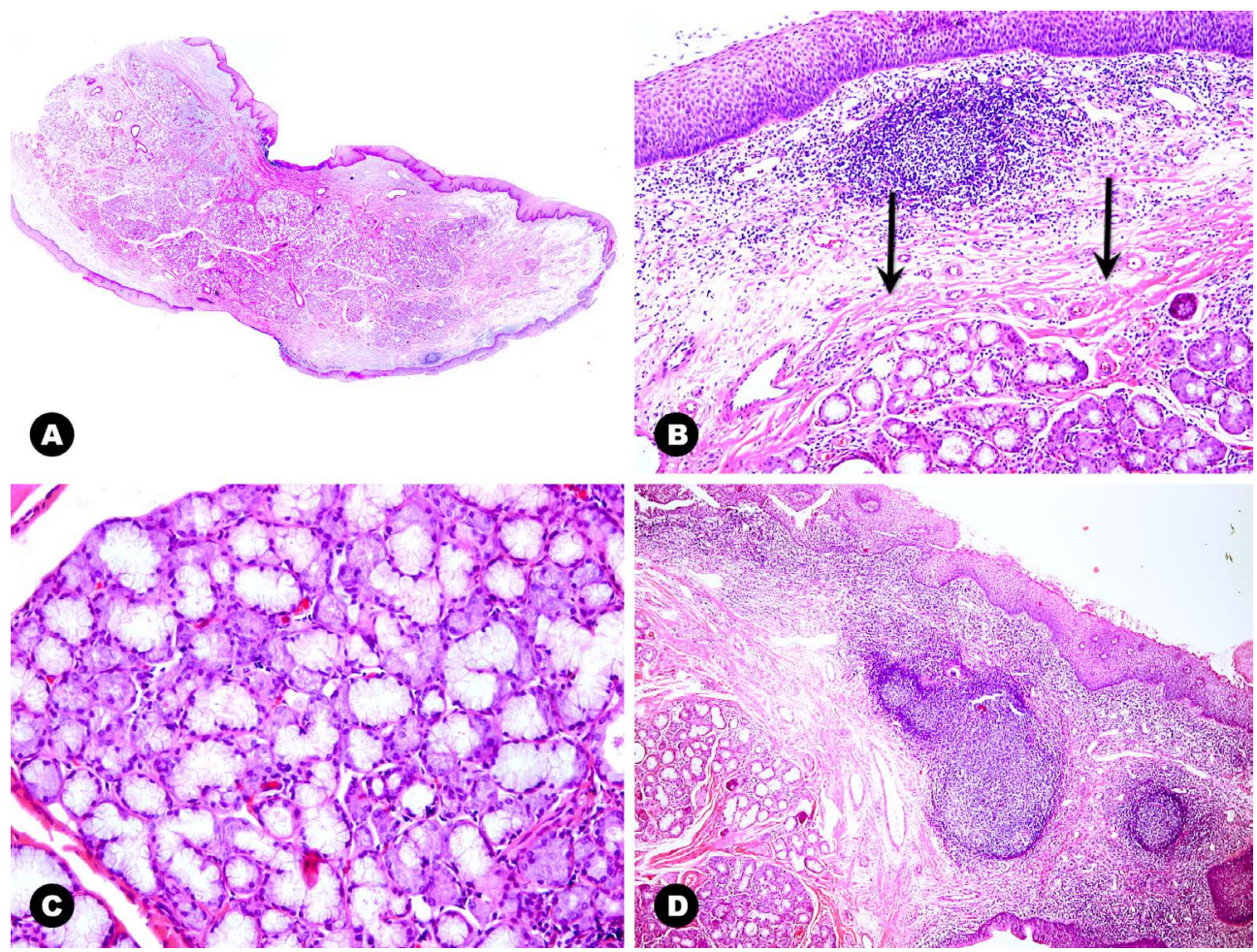

Figure 2. Microscopic findings. (A) Scan power view reveals a polypoid mass with relatively intact normal-appearing mucosa. (B) The medium magnification shows well-lobulated salivary glands, intermingled skeletal muscle bundles (arrows), focal lymphoid hyperplasia, and normal-appearing mucosa. (C) Salivary glands consisting of both serous and mucinous glands are lobulated by thin fibrous bands as seen in normal minor salivary glands. (D) The submucosal connective tissue layer reveals lymphoid hyperplasia that can be found in the normal tongue base.

encountered in daily practice. However, hamartoma of minor salivary gland has never been described, and its polypoid presentation is an even weirder thing. Although the histologic feature of this lesion favors benign clinical behavior, careful diagnostic workup and differential diagnosis are essential. In future, more cases should be collected to elucidate the etiology and true nature of this lesion.

\section{References}

[1] Gnepp, D.R. (2009) Diagnostic Surgical Pathology of the Head and Neck. 2nd Edition, Saunders/Elsevier, Philadelphia.

[2] Rosai, J., Ackerman, L.V. and Rosai, J. (2011) Rosai and Ackerman’s Surgical Pathology. 10th Edition, Mosby, New York.

[3] Campos, L.A. (1996) Hyperplasia of the Sublingual Glands in Adult Patients. Oral Surgery, Oral Medicine, Oral Pathology, Oral Radiology and Endodontics, 81, 584-585. http://dx.doi.org/10.1016/S1079-2104(96)80052-7

[4] Domaneschi, C., Maurício, A.R., Modolo, F. and Migliari, D.A. (2007) Idiopathic Hyperplasia of the Sublingual glands in Totally or Partially Edentulous Individuals. Oral Surgery, Oral Medicine, Oral Pathology, Oral Radiology and Endodontics, 103, 374-377. http://dx.doi.org/10.1016/j.tripleo.2006.04.012

[5] Mandel, L. and Romao, M. (2004) Sublingual Salivary Gland Enlargement. New York State Dental Journal, $70,24-27$.

[6] Kumar, S., Tiwary, S.K. and Khanna, A.K. (2009) An Accessory Tongue. Singapore Medical Journal, 50, e172. 
Scientific Research Publishing (SCIRP) is one of the largest Open Access journal publishers. It is currently publishing more than 200 open access, online, peer-reviewed journals covering a wide range of academic disciplines. SCIRP serves the worldwide academic communities and contributes to the progress and application of science with its publication.

Other selected journals from SCIRP are listed as below. Submit your manuscript to us via either submit@scirp.org or Online Submission Portal.
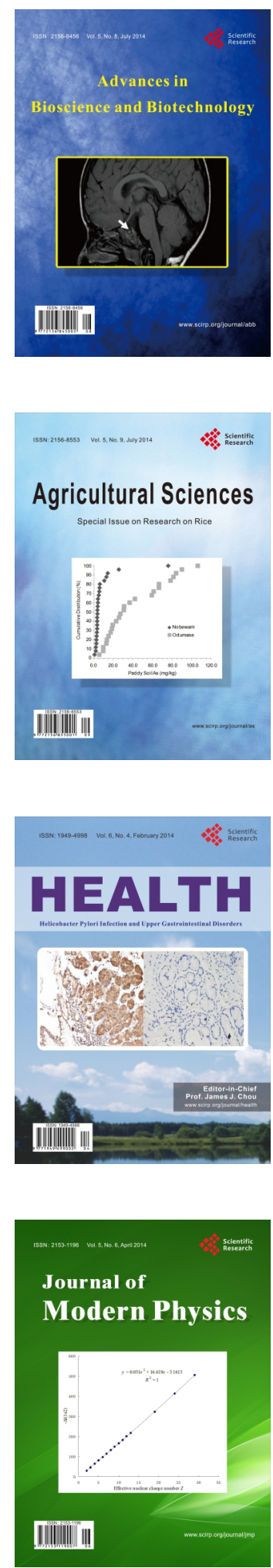
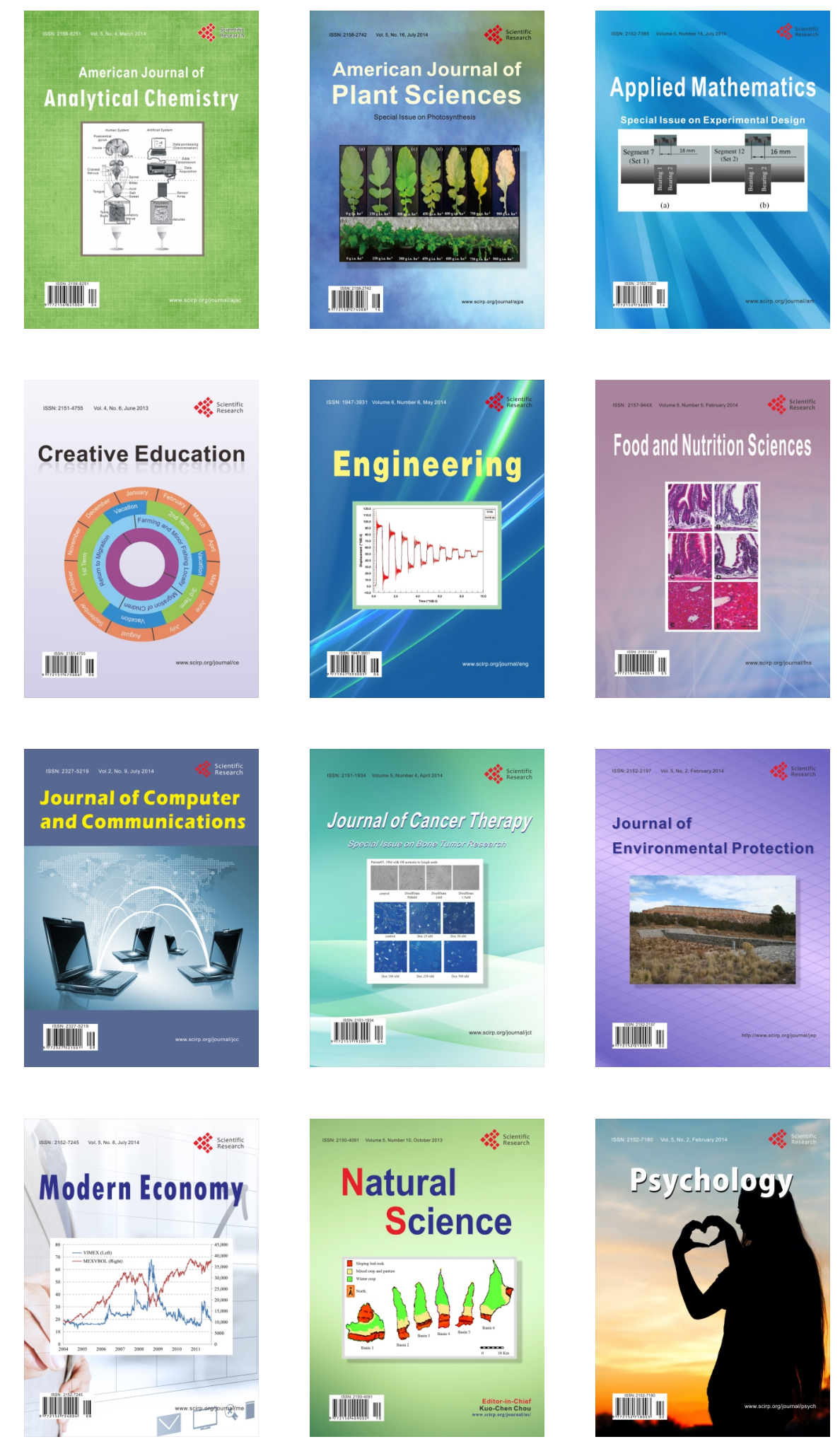